\title{
Renewables within the German Electricity System Experiences and Needs
}

\author{
Martin Kaltschmitt \\ Hamburg University of Technology (TUHH), Germany \\ kaltschmitt@tu-harburg.de
}

\begin{abstract}
During the last two decades renewable sources of energy as an environmentally friendly alternative to fossil fuel energy have gained greater importance within the German electricity system. Their share has increased from less than $4 \%$ to roughly one third of the gross electricity production in the last 25 years. Against this background, the goal of this paper is to present briefly the current status of the use of renewables within the German electricity system, to assess selected developments taking place during this development process and to identify given challenges and needs as well as the necessary actions to pave the road for a further use of renewable sources of energy. The political driver for the latter is the overarching goal to reduce Greenhouse Gas (GHG) emissions which have been confirmed within the Paris agreement signed by the end of 2015.
\end{abstract}

\section{INTRODUCTION}

As one consequence of the Kyoto Protocol, the European Union (EU) has implemented binding Greenhouse Gas (GHG) reduction targets. Following this overall goal also Germany has to reduce energy related GHG emissions substantially. Thus, a broad variety of policy measures have been implemented within the last decades among others to bring renewable sources of energy closer to the market and to exploit their possible contribution to this overarching political goal. Within the electricity sector the most important policy instrument implemented by the government has been and still is an act on the use of renewable sources of energy for electricity generation, i.e. the Erneuerbare-Energien-Gesetz
(EEG; electricity-feed-in law). Initially, within this act fixed reimbursement rates for different electricity generation options from renewable sources of energy have been defined. These fixed feed-in rates for "green" electricity are guaranteed by the government for 20 years and electricity from renewable sources is granted priority access to the public electricity grid independent from the actually given demand for electrical energy within the electrical distribution system. The remuneration of the fixed and guaranteed reimbursement for "green" electricity is financed by a surcharge to be paid by all electricity consumers except for an increasing number of large scale industrial consumers that face strong competition on international markets or whose expenditures amounts to a high share of their gross value added.

Based on such measures the share of renewables within the electricity supply system has increased significantly in Germany (Figure 1) from less than $4 \%$ in 1990 to roughly on third in 2015; within the last year all over close to 200 TWh (2015) of electricity has been produced from renewables and the overall German electricity consumption has been roughly 600 TWh (2015). Wind energy (i.e. onshore and offshore use) contributes with close to $45 \%$, biomass (i.e. solid biofuels, biogas) with $26 \%$, photovoltaics with ca. $20 \%$ and hydropower with less than $10 \%$. The avoided GHG emissions due to this renewable electricity generation have been summed up to more than 167.5 Mill $t$ (2015). Related to the overall energy related GHG emissions of close to 900 Mill t (2015) and this represents a share between 18 and $19 \%$. 


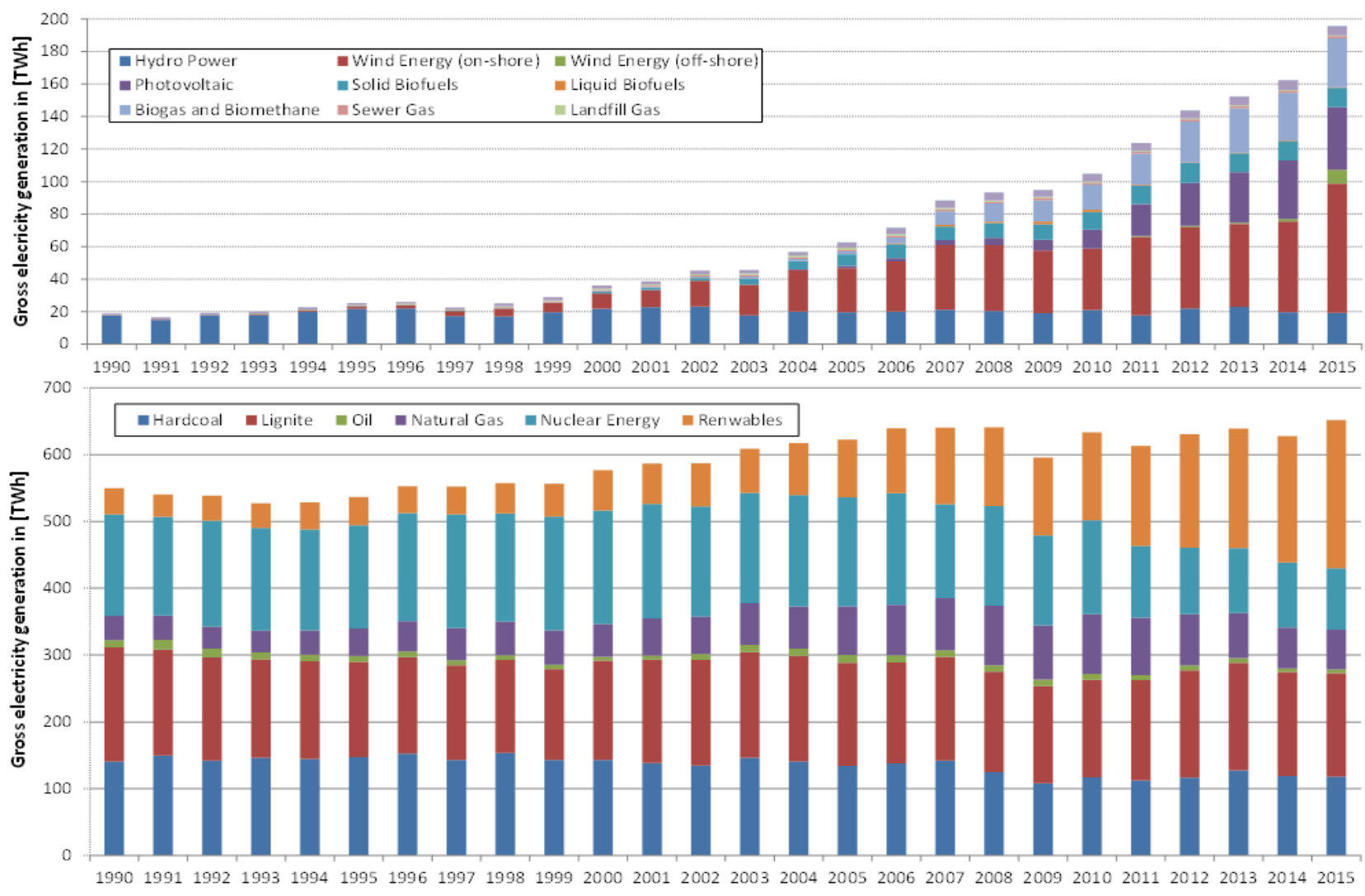

Fig .1. Gross electricity generation in Germany (lower chart: overall development, upper chart: electricity generation from renewables) (data according to [1, 2])

\section{EXPERIENCES AND LESSONS LEARNED}

Wind energy. As a consequence of the promising feed-in tariffs and the stable long term conditions guaranteed by the legal framework, electricity generation from wind energy has steadily expanded from basically zero around the year 1990 to 79.3 TWh (only onshore installed wind mills) in 2015. This increase in power generation has taken place in parallel with a strong and impressive technological development of the wind mill technology. Thus during the 25 years between 1990 and 2015 wind mill technology has been characterized by a strong increase in the installed electrical power per unit from roughly 100 to $250 \mathrm{~kW}$ in the late 1980s / early 1990s to more than 5 to $6 \mathrm{MW}$ today. This power increase throughout these roughly 25 years has been accompanied by clear reductions in specific market prices as well as continuously increasing overall efficiencies and reliabilities. Beside this, wind mills become more environmentally sound, their operation much more reliable, their safety features more advanced, and their interaction with the electricity grid more system compatible. In parallel, wind mill manufacturing in Germany has been developed to a fast growing large scale innovative industry sector with high technological standards and a strong export orientation during this quarter of a century due to globally strongly growing markets. This impressive development has been supported and accompanied by the development and implementation of binding and non-binding guidelines and standards defining various side aspects for the increasingly larger wind mills (e.g. noise, safety and environmental standards); i.e. a process has been takening place to develop the wind mill industry to industry branch fully integrated within the German overall economy. The wind mills currently available on global markets from the German manufacturers present a fully marketable technology easily adaptable to locations with a different wind supply, which can even support grid stability.

This development has been accompanied by considerable and controversial as well as very emotional discussions related to the visual impact of wind mills on the landscape due to their over time strongly increasing dimensions as well as the rotor rotation putting movements into a formerly more or less static landscape. Thus, with an ongoing 
expansion of the installed wind mills and thus an increased use of this technology the acceptance by the local population as well as promising wind mill sites with high average wind speeds continuously decreased. Especially in areas where many wind mills have been installed due to favorable wind conditions (e.g. in areas close to the North Sea coast) citizens' initiatives became more active and hindered or even prohibited further installations. To alleviate this obstacle, the German government promoted the installation of offshore wind farms in the North Sea as well as the Baltic Sea. Advantages of this approach to go offshore are significantly higher electricity yields at a certain spot due to considerable higher wind speeds compared to most onshore locations and a much better acceptance by the public. Severe technological challenges clearly higher specific electricity generation costs and still hard to fulfill legal conditions for the protection of the fragile offshore ecosystems present strong disadvantages of this approach. To overcome the challenging environmental, economic and site-specific conditions given at locations more than $50 \mathrm{~km}$ off the North Sea coast in water depths of $30 \mathrm{~m}$ plus hindering an increased wind energy use, the existing political framework has been adjusted to set appropriate conditions to foster offshore wind energy utilization; i.e. the feed-in tariffs have been increased several time to compensate the given technical risks and the high costs necessary to master the challenging conditions regarding location as well as to fulfill the environmental protection requirements controlled by the local authorities. Even due to these challenge in 2015 already 8.7 TWh provided from offshore located wind mills have been feed into the German electricity grid in addition to several additional offshore wind parks which are under construction. In parallel great effort is put into the development of advanced wind mill technologies operating reliable even under the rough and challenging environmental conditions offshore as well as the necessary foundations to fix the mills securely on the sea ground; experiences available so far have shown that there is indeed a huge demand to adjust the wind mill technology to face successfully the significantly different environmental conditions given at a certain offshore location. The developments in the years to come will show if the cost reductions to be expected with an increasing installation of offshore wind parks combined with a much better wind supply within these locations will offset the additional investment and maintenance costs of offshore installations. If this turns out to be the case, this option offers huge electricity generation potentials as well as immense markets for equipment and services globally. Besides, on the longer term a significant share of the electricity needed by the German population might come from offshore wind parks due to the huge potentials as well as the relatively high wind speed.

Photovoltaic (PV). The support scheme implemented by the German feed-in law has originally been designed to support electricity generation systems based on renewable sources of energy to become marginal profitable by the owner / operator. Beside climate protection as the main driver the intention was to help these technologies to become market mature (i.e. to overcome the market entrance barriers) and in parallel to treat the electricity customer / the payer of this additional financial burden with care with respect to the resulting costs (i.e. to minimize the additional costs for the final user of the electricity). This has been especially true for PV systems, which were politically intended to be operated by individuals in the one digit kW-range and to be installed on dwelling houses without additional land use to increase acceptance; the original politically intended long term vision was to upgrade each dwelling house to a small power plant. These circumstances combined with the still relatively high costs and limited return on investment some 10 years ago, the share of PV within the German electricity system was almost negligible till 2006/07. In the following years, prices of PV modules dropped fast and significantly due to a strong development of the respective production capacities especially in China among others due to the incentives granted by the Chinese government. These strong decreases in module prices in these days, combined with the now relatively high reimbursement rates guaranteed and continuously confirmed by law resulted in a rapid development of small and especially large scale PV systems operated by individuals as well as financially strong market participants (e.g. investment funds, utilities, pension funds). And this relative profitability during these days increased on a daily basis because the feed-in tariffs defined within the German feed-in law have not been adapted adequately in parallel; i.e. it has been very profitable to invest in PV systems for financially strong investors as well as private market participants. This development shows clearly the disadvantage of fixed reimbursement rates with an unlimited expansion option as it has been realized within the German feed-in law these days. If market 
prices change rapidly due to new production facilities and/or a strong expansion of the market volumes the reimbursement rates could not be adjusted fast enough due to the time consuming administrative procedures necessary to amend an existing law.

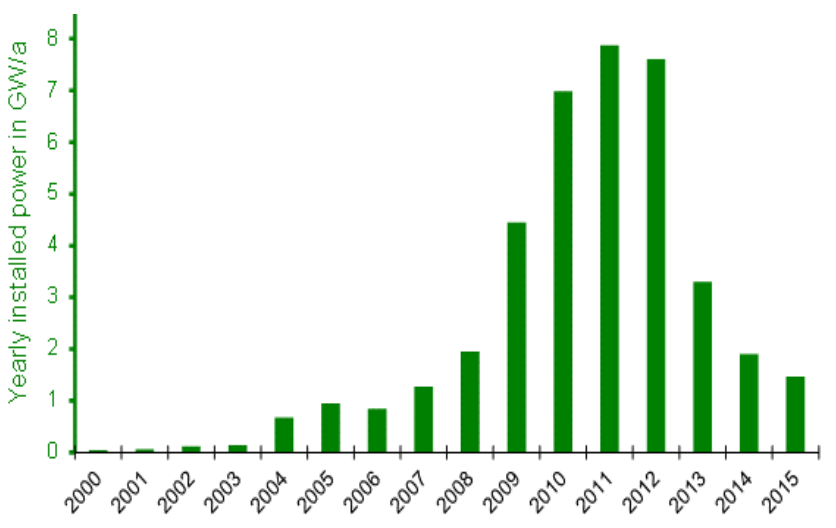

Fig .2. Yearly installed PV capacity in Germany (data according to [7]).

This development results in an installation of roughly 7 to $8 \mathrm{GW} / \mathrm{a}$ in PV systems in the years 2010, 2011 and 2012 (i.e. $22.5 \mathrm{GW}$ within these three years, Figure 2). During the beginning of this time period roughly half of the global PV module production has been installed only in Germany, this share decreased then to about one third in 2012. Thus, the (subsidized) German market helped significantly to pass through the learning curve, to overcome the market entrance barriers, and therefore to bring the prices for PV modules globally down. As a consequence the foundation of the worldwide market break-through of PV systems has been set these days based on the money of the German electricity consumer. As a result of this impressive development, the surcharge to be paid by electricity consumers in Germany has reached roughly 10 Bill $€ / a$, which corresponds to $0.0263 € / \mathrm{kWh}$ to be paid according to the legal frame work with the monthly electricity bill mainly by the household and other small customer of electrical energy (some large scale industrial consumers of electricity do not have to pay this fee due to the legal situation in Germany). In total, the overall capacity of the installed PV modules reached 39.7 GW in 2015, providing 38.4 TWh (2015) of electricity.

To limit the significant cost increase and to meet the instructions from the European Union (EU), the legal support scheme for renewables in general and $\mathrm{PV}$ in particular has been changed completely in recent years. A bidding system with a clearly defined cap (i.e. a maximum amount of electrical capacity to be installed each year) has been introduced. The very limited practice with this support scheme has shown so far that the aspired goal of $1.5 \mathrm{GW} / \mathrm{a}$ of PV capacity to be installed have not been reached due to numerous reasons related to the design of this support concept as well as a strongly changing environment within the electricity market.

Solid biofuels. The electricity-feed-in law has also triggered a significant and unexpected increase in electricity production based on solid biomass. In 2015, ca. 18.2 TWh of electricity and 19.3 TWh of heat have been produced by co-generation (CHP) from solid organic matter. The technical maturity of an energy generation from solid biomass based on CHPsystems under operation within the wood processing industry already since generations resulted in a rapid market increase in 2000 as soon as the feed-in law was opened up to electricity generation from such fuels (Figure 1). These existing plants operated by industry are needed to produce electrical energy for the various wood processing facilities, to provide heat for drying the manufactured wood products, and to get rid-off the wood waste piled up during wood processing. After the implementation of this option within the feed-in law new plants have been erected by investment companies as well as various utilities using contaminated wood waste. Thus, this legally pushed increase of energy generation from solid biomass has been taken off on decades of experiences available already within industry from the construction as well as the operation side. Therefore an immediate roll-out of this technology has been possible and has been realized successfully. However in argumentum e contrario basically no major new technological advancements have taken place. Thi has also been one of the main original goals of the feed-in law; i.e. only state-of-the-art technology has been installed within the growth process and thus for example no gasification facility promising higher electrical efficiencies has been realized due to potentially too high technological and thus economic risks.

All over Germany started to use on large scale demolition wood as a fuel for electricity generation and/or for combined heat and power (CHP) starting roughly in the years around 2000 . Independently from this, since the 1990s this fuel has been used extensively for power and/or heat generation in such 
European countries where a CO2-tax has been implemented and/or low emission standards have been valid; i.e. during these days demolition wood incurred in Germany have been exported e.g. to Italy and to Sweden. However, with the implementation of the feed-in law in Germany this development has come to a stop. Subsidizing electricity from (contaminated and non-contaminated) wood (waste) and thus developing own wood-fired power plants in Germany has induced not foreseen market and thus price effects within the markets for such solid biofuels. Prices for fuel wood / demolition wood / waste wood have increased significantly and waste wood has changed from being considered waste bringing money(i.e. the institution producing the waste wood has to pay deposing fee to the waste management company to get rid of this waste) to a valuable energy carrier with a market price defined by the average heating value; (i.e. power plant operators formerly received wood waste disposal fees and now they have to pay for the waste wood according to the average heating value). The increased demand for fuel wood due to an over-expansion of the amount of the respective power plants furthermore resulted in an overall price increase for all types of fuel wood / waste wood for industrial/ energetic purpose Thus, potential economic profits to be exploited by the owner of a power plant using waste are not possible any more. But, still the producer of the waste wood has to pay to get rid of this material. The economic margin in between has been exploited by fuel wood / waste wood traders. Due to these effects the profitability of power plants fueled by waste wood have been lowered considerably. This development has increased the economic pressure on power plant operators / owners dependent economically on disposal fees or very low fuel prices. Resulting effects have been the shut-down of some of these newly build power plant facilities and/or the conversion of a wood fired power plant to a coal fired facility.

Besides, also the prices for virgin wood fuels have increased. This price increase have also had a strong influence on the market prices for wood as a raw material and thus on the feedstock used by the wood processing industry. This development has been very much appreciated by most of the producers (i.e. the forest owner) but not at all by the wood processing industry interested in low feedstock prices. This was the reason why the German wood processing industry has been strongly opposed to this part of the feed-in law and thus has campaigned heavily against an electricity generation from wood even due the fact that an electricity generation from wood waste piling up during wood processing has been and still is realized to a large extend within their own factories. The consequence of these political activities of the various responsible associations has been a strong cut of the reimbursement rates preventing economically the use of virgin wood within large scale power plants as well as large CHP-plants.

Additionally, nowadays basically the overall available amount of demolition and other wood waste that is not useable as a raw material for producing recycled wood products (e.g. chip board, oriented structural board) is used energetically. Thus the installation of new wood waste fired power or CHP plants has come to an abrupt stop when the fuel wood demand of the existing plants exceeded available potentials of demolition wood / waste wood in Germany. This development is supported by the fact that reimbursement rates are too low resp. the prices for fresh wood are too high to allow the use of significant amounts of virgin wood material within the large scale energy market. As a consequence, electricity generation from solid biofuels has been more or less stable in recent years because the yearly incurred demolition wood / waste wood is more or less constant in Germany and an increased import is not possible due to economic constraints.

Biogas. Also biogas production and a subsequent electricity provision have shown a remarkable development in recent years in Germany. Starting basically from a plant inventory of some 100 "homemade" biogas plants some 25 years ago the technology has become technically mature with highly efficient, easy to operate, reliable and environmental sound plants. In 2015, close to 9,000 biogas plants (Figure 3) have been in operation primarily within the agricultural sector. These plants produced roughly 31.8 TWh of electricity and in parallel 16.8 TWh heat in 2015. 


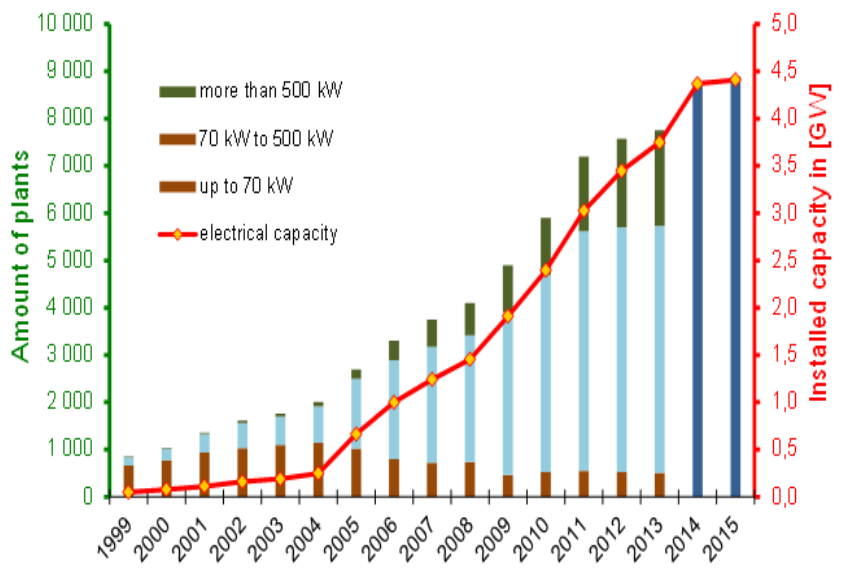

Fig .3. Development of the installed capacity in biogas plants in Germany (2014 and 2015: preliminary data; data according to [7]).

This biogas production is based on two different types of feedstock: organic residues and wastes as well as energy crops. Both material streams are a priori limited.

- Organic residues and wastes suitable for biogas production, e.g. animal manure, organic urban waste fraction from household waste, organic waste from the food processing industry, need to be collected and transported. But, such organic material is characterized by high water content typically contained within such organic material streams and a low energy yield. Thus, this material cannot be transported over long distances due to economic reasons (i.e. mainly water is transported). In contrast, due to "economy of scale"-effects, biogas plants become specifically clearly cheaper with increasing capacity and very small biogas plants are typically specifically extremely expensive. Due to this dilemma only a (small) part of the overall available organic residues and wastes are used so far, even considering the fact that the subsidizing scheme supports the use of such organic matter in small scale biogas systems with a bonus, which is however too low to fully exploit the existing technical potentials. Thus the debate on how the existing agricultural and non-agricultural waste and residue streams could be utilized in the most efficient manner related to technical, economic and environmental aspects taking also acceptance aspects into consideration is still ongoing. It is not expected that this discussion will come to an end in the months to come.
- Fertile agricultural land is limited and cannot be expanded at least in Germany. However, in recent years, slightly increasing yields of roughly 1 to 2 $\% / a l-$ together with a stable population with more or less a constant food pattern resulted in an ongoing reduction of the demanded agricultural land for food production. Thus during the last decades an increasing amount of agricultural land has not been needed any more to produce food and feed for the domestic market. This development will most likely be ongoing and even accelerate in the years to come because the German population will probably decline in the future due to low birthrates; this is supported by an ongoing trend towards a higher share of vegetarian food. To keep this "surplus" land fertile energy crops can be produced on this agricultural land which is basically not needed for food and fodder production any more - if these land resources will not be used to produce food for an increasing export of food "Made in Germany" and/or set aside based on public money e.g. due to ecological considerations (e.g. increase in biodiversity). Additionally, the availability of fertile agricultural land is also very much influenced by other regulations, e.g. the Common Agricultural Policy (CAP) of the EC, land requirements for other energy crops, e.g. rape for Biodiesel production, the need for biomass as a raw material, e.g. for the chemical industry, as well as the agricultural production intensity in Germany. Taking these influencing parameters into account, the potential of producing energy crops is already used to a considerable extend (currently substrates for biogas plants are grown on ca. 1.4 Mill ha and the overall agricultural land in Germany is 11.8 Mill ha). Additionally public acceptance of growing energy crops is limited and some NGO's are working hard to reduce the amount of land used for this purpose due to ethical and/or environmental objections. Beside this, agricultural feedstock production for biogas plants is expensive and thereby contributes to high electricity generation costs. Thus, also discussions on the energy provision costs of biogas are on the political agenda. Thus it is not expected that the amount of land used for the production of biogas feedstock will expanded significantly in the years to come.

Consequently, a further expansion of biogas production will reach sooner or later its limit in Germany. This is independent from the fact that 
biogas production is anyway controlled by the reimbursement rate granted by the feed-in law which has been step by step reduced in recent years. Thus, after the end of the boom phase in recent years the industry producing and constructing biogas plants urgently need to find new and/or additional markets for their products nationally and in particular internationally if they want to survive and thus stay in business in the longer term. In this respect the food processing industry seems to be a promising commercial market for biogas plants. Companies providing food products produce necessarily organic waste streams to be treated and/or utilized in one way or another in most countries globally due to environmental reasons.

Additionally these companies always need energy, i.e. heat and electricity, to process the food biomass to a marketable food product meeting the needs of the customer. The use of these organic waste streams together with waste water polluted with organics typically provided necessarily in parallel - to provide biogas could contribute significantly to solving both challenges. This is a reason why some countries have already started to force the food processing industry to install biogas plants as an adequate measure for the management of the produced organic waste streams, for environmental protection, for "green" energy provision and for cost reasons as well as for a better acceptance within the local population. These arguments and developments are some reasons why in Germany there is currently a tendency to reroute the developments within the biogas sector towards the use of organic waste streams from commerce and industry as well as from households instead of expanding the production of biogas from energy crops to be produced on fertile agricultural land. The fact that the increasingly more local waste management companies start to collect organic household waste separately adds up to this.

Geothermal energy. The feed-in law grants also feed-in revenues for electricity from geothermal energy. Due to the less promising (i.e. average to below average) geological conditions in Germany compared, for example, e.g. to New Zealand, the Philippines, and Iceland, the reimbursement rate has been defined generous according to the status of knowledge more than 15 years ago when geothermal electricity generation has been included within the legal subsidizing scheme. Based on this a gold rush mentality developed visible in popping up of lots of different companies with basically no relevant experience promising very high revenues to public and private investors. Some of these companies have been successful in convincing communities to invest in geothermal CHP plants. But none of these projects have been completed in time achieving the aspired performance figures. Some of these projects have even been terminated in the design phase already. Others have not been successful in finding enough hot water to meet the necessary design criteria (i.e. temperature level, specific production rate and water quality) within the unlocked reservoir. Some projects even failed in unlocking the geothermal reservoir due to severe technical problems during the drilling process.

This invidious situation has also been recognized by the German government. To give the emerging geothermal industry a chance to develop towards a reputable industry branch yearly several 10 Mill. $€$ of public money for research and demonstration activities have been provided to support at least two or three geothermal CHP plants to go successfully into operation. Besids, the reimbursement rate has been increased several times to improve the economic incentive to bring such geothermal plants closer to the market. In parallel, subsidies have been made available by the state-owned KfW-bank to develop also heat distribution infrastructure to allow the sale of "green" geothermal heat provided in parallel to geothermal electricity within the geothermal CHP units.

After the first geothermal energy systems have gone successfully into operation with some years of delay several new projects have been initiated. Most of them failed; but roughly a handful has been realized. Thus, due to these administrative measures so far 8 geothermal power resp. CHP plants are under operation in Germany with an overall installed electrical capacity of roughly $33 \mathrm{MW}$. These plants provide 0.13 TWh of electricity and in parallel $1.2 \mathrm{PJ}$ of heat (2015).

The experiences gathered during the operation of these plants have been very much mixed. One plant initiated a weak seismic incident. Due to the resulting fear of additional earth shattering and the respective disapproval of the local people this plant is only allowed to operate in part load to avoid or at least to minimize further seismic effects. Other plants do have significant economic problems among others due to expensive maintenance efforts especially with the submersible pump transporting the geothermal fluid 
from the underground to the above ground. These are some of the reasons why there is basically no visible development in this field so far. The only exemption is the area around Munich where the Molasse Basin shows relative stable geological conditions allowing for a reliable CHP-operation. Additionally in Munich a big district heating system has been installed during recent decades which can distribute geothermal heat on a large scale to the final customer, but even there the available potential does not exceed a couple of plants.

\section{FINAL CONSIDERATIONS}

Renewable sources of energy have gained more importance within the German electricity system. Important aspects can be summarized as follows (see also [3-11]).

- The use of renewable sources of energy can be expanded significantly within the electricity system by administrative measures; the development in Germany during the last 25 years has proven that such a political strategy can be successful (even to due the fact that not all implemented measures and each renewables source of energy getting financial support have proven to be a success story). With a share of roughly one third of the electricity generation coming from renewables in 2015 two main political goals of this legally controlled development has been achieved: the amount of greenhouse gas (GHG) emissions has been significantly reduced and the share of domestic energy carrier within the electricity system has been noticeable increased.

- If the legal frame work is set adequately and the overall goal of such a politically intended development is clearly defined and widely accepted by the majority of the population (as it is still the case in Germany) such a strategy can push the technological development and thus create additional benefits for the overall society, e.g. availability of new jobs, creation of value in rural areas, and set-up of export oriented industry branches. From a purely technological point of view the following experiences could be observed.

A. If a conversion technology has already been available on the market and a significant growth potential is given the legal frame could trigger an impressive und unforeseeable technological development; in Germany this has been especially true for wind mill technology and photovoltaic systems as well as for biogas plants. New and not market mature technologies as well as options with a limited expansion potential have not or to a very limited extent, been further developed (e.g. electricity generation from solid biofuels). Other electricity provision options characterized by too much uncontrollable risks related to the potential return on investment together with insufficient and error-prone technological solutions failed respectively and showed only a very limited development (e.g. geothermal electricity generation).

B. Due to the market introduction of conversion technologies using renewable sources of energy based on administrative measures considerably more efficient - and thus theoretically cheaper conversion plants have been developed throughout recent years; the development of completely new industry branches has been a consequence. This development has been supported by yearly decreasing reimbursement rates to force industry to come increasingly closer to electricity generation costs competitive on global energy markets. In parallel, technological, economic and environmental as well as societal and safety demands to be fulfilled by these plants have increased also due to local demands promoted especially by environmental NGO's. To fulfill these numerous and partly contradicting demands from various sides the respective costs have increased. Hence, the achieved cost reduction due to improved technological solutions was compensated respectively. overcompensated by higher technological, safety and environmental as well as societal standards. Thus as a consequence of this development, conversion systems based on renewables have become more efficient and technologically more mature over time but not necessarily specifically cheaper.

- To initiate and control such a transformation process towards an increased use of renewables, public money as well as a reliable and stable long term strategy implemented by the government is absolutely needed; if such a strategy is designed well the benefit for the overall economy could (and should) overcompensate this necessary initial investment based on public money. For Germany this has only been partly successful. Within the wind 
sector a strong industry for manufacturing wind mills has been developed creating value also in rural and economically less developed areas. This has not been the case for photovoltaic systems. Here, other countries have been much more successful in building up a prospering industrial infrastructure and German companies producing PV modules have gone bankrupt to a large extent.

- So far, the German legal framework has supported electricity generation from renewable sources of energy. This has been realized with a broad approach to give all options a realistic chance at the market. However, with an increasing use of these options within the overall electricity system cost aspects gain more importance. The consequence is that the public and political discussion moves more in the direction of recommending a further financial support only for the most cost efficient options characterized by huge unexploited potentials and a high public acceptance. According to current knowledge and based on today's technology, these are wind mills and photovoltaic systems. These electricity generation options show a strong fluctuating electricity production characteristic. Thus the next move is to find concepts as well as technologies to integrate significantly higher shares of such generation plants within the electricity supply system by guaranteeing an ongoing high security of supply throughout the overall year. Thus the current discussion focuses on the identification of technologically efficient, environmentally sound and economic viable as well as socially acceptable solutions.

Altogether, the German example has shown that a strategy to use renewables more intensively within the overall energy system is possible and could be successful in terms of an increased energy provision as well as a significant reduction in greenhouse gas emissions.

\section{REFERENCES}

[1] Energy statistics. Available: http://bmwi.de/DE/Themen/Energie /Energiedaten-undanalysen/energiedaten.html.[May 10, 2016].

[2] Energy statistics. Available: http://www.agenergiebilanzen.de/6-0-
Primaerenergieverbrauch.html. [May 10, 2016].

[3] M. Kaltschmitt, H. Hartmann and H. Hofbauer (eds). Energie aus Biomasse: Grundlagen, Techniken und Verfahren. 3rd edition. Springer, Berlin, Heidelberg, 2016.

[4] M. Kaltschmitt, W. Streicher and A. Wiese, A. (eds). Erneuerbare Energien - Systemtechnik, Wirtschaftlichkeit, Umweltaspekte. 5th edition. Springer, Berlin, Heidelberg, 2013.

[5] P. Keineidam and M. Kaltschmitt et al. Renewable power generation 2013. Renewable energy focus, issue $7 / 8$ (2015), pp.16 $-37$.

[6] K. Bloche-Daub, J. Witt, M. Kaltschmitt and S. Janczik. Erneuerbare Energien - Globaler Stand." BWK, vol. 67, 7/8, S, pp. 6-22, 2016.

[7] Lenz, K. Naumann, M. Kaltschmitt and S. Janczik. Erneuerbare Energien Erkenntnisstand 2014 in Deutschland BWK, vol. 68, 5, pp. $60-80,2016$.

[8] S. Janczik and M. Kaltschmitt. Statusreport Tiefe Geothermie 2015: Nationale und internationale Nutzung Erdöl Erdgas Kohle, vol. 131, 7/8, pp. $301-307,2015$.

[9] M. Kaltschmitt D. Thrän and J. Ponitka. Holz als Energieträger - Möglichkeiten und Grenzen im Kontext von globalen Entwicklungen. Forst und Holz, vol. 65, 12, pp. 18 - 25, 2010.

[10] S. Janczik, M. Kaltschmitt, H. Rüter. Anthropogen induzierte seismische Aktivitäten bei Nutzung des tiefen Untergrunds Energiewirtschaftliche Tagesfragen, vol. 60, 8, pp. $34-39,2010$.

[11] M. Kaltschmitt and D. Thrän. Logistik bei der Versorgung von Anlagen zur energetischen Nutzung biogener Festbrennstoffe Anforderungen und Randbedingungen." Zeitschrift für Energiewirtschaft, vol. 30, 4, pp. 247 - 256, 2006. 